\title{
ARTIGO
}

\section{PROFANANDO O “PAPEL" DA ESCOLA? NARRATIVAS PÓS-MODERNAS SOBRE O PROCESSO SOCIAL DE ESCOLARIZAÇÃO}

Profaning school "paper"? Post-modern narratives about the schooling social process

Profanando el "papel" de la escuela? Narrativas posmodernas sobre el proceso de escolarización social

Clívio Pimentel Júnior

Universidade Federal da Bahia - Brasil

\section{Maria Inez da Silva de Souza Carvalho}

Universidade Federal da Bahia - Brasil

\section{Resumo}

Esse artigo de posicionamento tem como objetivo discutir o quanto a visão instrumentalista e pragmática, presente em várias correntes de estudos sobre a escola vem historicamente minando o papel social desta instituição e do trabalho docente através da alegação de que a escola e o seu corpo docente estão sempre "atrasados" e/ou "desgovernados" em relação às demandas contemporâneas provenientes do meio social e/ou às certezas passadas, respectivamente. Seguindo linha de argumentação distinta, defendemos que a escola persegue objetivos próprios com fins em si mesmos, em consonância com o projeto social de escolarização. Nessa perspectiva, o processo de escolarização pode não ser meio para atingir determinado fim externo ao período escolar quando inserido na vida em sociedade, mas ter um fim sem si mesmo, uma vez que a escola é parte da sociedade independente de estar ou não submissa às necessidades e demandas sociais. Em acordo com tal linha de argumentação, torna-se conveniente aceitar a escola tal como ela é, uma escola fraca.

Palavras-chave: Escola fraca. Liberdade. Pós-modernidade.

\section{Abstract}

This position paper aims to discuss how the instrumental and pragmatic view, present in many current studies of the school, has historically undermined the role of this social institution and the teacher's work by claiming that the school and its faculty are always "late" and/or "unruly" 
in relation to the demands from the social environment and/or past certainties, respectively. Following different line of argument, we hold that the school pursues its own objectives with ends in themselves, in line with the social project of schooling. From this perspective, the process of schooling cannot be means to an external end to the school term when inserted in society, but having an end in itself, since the school is part of society regardless of whether or not subjected to the needs and social demands. In agreement with this line of argument, it is appropriate to accept the school as it is, a weak school.

Key Words: Weak school. Liberty. Post-modernity.

\section{Resumen}

Este artículo de posición tiene como objetivo discutir cómo el instrumentista y pragmático vista, presente en muchas actual Escuela de estudios, históricamente ha socavar el papel social de esta institución y de la labor docente a través de la afirmación de que la escuela y sus profesores son siempre "tarde" y / o "sin guía" en relación a las demandas del entorno social y / oa las certezas del pasado, respectivamente. Siguiendo distinto línea de argumentación, argumentan que los persigue escolares poseen metas con fines en sí mismos, de acuerdo con el proyecto social de la educación. Desde esta perspectiva, el proceso de la educación no puede ser medio para un fin externo al curso escolar cuando se inserta en la sociedad, pero que tiene un fin en sí mismo, ya que la escuela es parte de la Sociedad independiente de si es o no sumisos a necesidades y demandas sociales. De acuerdo con esta argumentación, es conveniente aceptar la escuela como es, una escuela débil.

Palabras-clave: Escuela débil. Libertad. Post-modernidad.

\section{Em defesa de uma escola "fraca": profanamentos pós-modernos}

A limitação da linguagem e da escrita obriga a inventar cada vez mais palavras, mais figuras, mais argumentos, mais textos para dizer melhor. Se tivéssemos uma linguagem perfeita, não precisaríamos mais nem falar nem escrever.

Jeanne Marie Gagnebin

Em nossa trajetória na pesquisa em Educação, temos defendido posicionamentos que derivam, em grande parte, do que vimos semanalmente discutindo em reuniões do nosso grupo de pesquisa e, neste artigo, expressamos alguns deles. Por outra parte, tais posicionamentos derivam de constatações, com rigorosas revisões, desenvolvidas em uma pesquisa de mestrado defendida no Programa de Pós Graduação da Faculdade de Educação, Universidade Federal da Bahia. De modo geral, tratam-se de estudos que perseguem concepções e noções fracas (VATTIMO, 2007), menos mecânicas, não reversíveis e não previsíveis (PRIGOGINE, 1996), quando o assunto é o rumo dos processos sociais de escolarização. Buscamos em nossas investigações, de modo geral, e neste trabalho, de modo 
específico, problematizar o potencial heurístico dos vocabulários e narrativas modernas e iluministas, de notável inspiração materialista, sobre o papel escolar e sua vontade de “endireitar” (ANDREOTTI, 2013) a sociedade pelo conhecimento e pela razão iluminista ocidental, o que, em última análise, culmina em um tratamento mecânico e reversível da própria história das ideias e sistemas de pensamento sobre a escolarização. Temos constatado que tal pensamento idealista culmina numa leitura pragmática e utilitarista da própria escola, como se esta respondesse unicamente aos ditames e necessidades sociais, o que pode ser perigoso, na medida em que consideramos que "o excesso de regulação é potencialmente mortífero ou, ao menos, desativa a tensão vital pela qual uma comunidade [em nosso caso, a comunidade escolar] se sente responsável por si mesma e assegura assim a própria conservação de si." (MAFFESOLI, 2005, p.44). Temos defendido que, em última análise, tais narrativas sobre o papel da escola são marcadas pela gana de querer controlar e concluir ${ }^{l}$ (MAFFESOLI, 2005; 2008) as experiências sociais e práticas simbólicas educacionais de atribuição de sentidos e construção de significados na medida em que, ambicionando uma total correspondência entre o signo, o significante e o significado sem espaço para as erosões da linguagem, para o que vaza nas interpretações, para os desvios no uso de artefatos culturais, pretendem estabilizar e ordenar a tudo e a todos pelo conhecimento escolarizado "esclarecido"; isto é, fazer as práticas simbólicas corresponderem pari passu à escritura racional escolar, que mantém sobre estas o poder de uma exterioridade conformativa (CERTEAU, 2009; PIMENTEL-JÚNIOR, 2015).

Apresentamos, a seguir, os referentes entre os quais vimos caminhando em nossos estudos como forma de, minimamente, introduzir os pensamentos e autores que vêm inspirando nossas investigações. Anunciamos alguns posicionamentos filosóficos e teóricos adotados neste trabalho, cuja matriz paradigmática faz referência ao que se convencionou denominar de Pós-Modernidade. Temos permanecido cônscios de que, ao operar com tais convenções, formadas por meio de acordos continuamente revisados entre pares, na tentativa de dar um fechamento, mesmo que provisório, a um determinado significante, - em nosso caso, o significante Pós-modernidade - por mais amplo que seja seu alcance heurístico, deixamos de fora determinados aspectos diferenciais que não podem ser exaustivamente mapeados. Temos defendido que isso não significa que devemos abandonar tais acordos e convenções em nossos trabalhos; significa apenas que temos estado atentos para o fato de que

\footnotetext{
1 Para Maffesoli, as ganas de controle são marcadas, pode-se dizer, por "uma espécie de efeito perverso, querendo alcançar a perfeição da unidade; isto é, pretendendo negar ou recusar a diversidade, a pluralidade de gostos e de interesses, acaba-se na degradação, na queda do conjunto social, quando não simplesmente na intolerância com seu cortejo de exações.” (MAFFEOSLI, 2005, p. 37-38)
} 
seu potencial representativo nunca abarca todas as demandas da diferença entre os significantes compartilhados em uma convenção.

A noção de Pós-Modernidade aqui apresentada está em consonância com a caracterização feita por Santos (2006), Lyotard (1988) e Vattimo (2007). Tratam-se de autores que compreendem este movimento de pensamento como um ethos de pensamento diferente, marcado por um afastamento radical do vocabulário Moderno e suas pretensões racionalistas de planificação da história e do campo social. De acordo com Lyotard (1988), por exemplo, podemos entender que o pensamento pós-moderno trata-se de um movimento que não apela aos metadiscursos explicativos, isto é, aos discursos erigidos sobre os conceitos de "razão", "sujeito", "totalidade", "verdade", "emancipação", "progresso" etc. De acordo com ele, o pósmoderno, enquanto condição da cultura nesta era, caracteriza-se exatamente pela incredulidade perante esse metadiscurso filosófico-metafísico, com suas pretensões atemporais e universalizantes ${ }^{2}$. Para ele, a conseqüência mais imediata deste novo cenário foi tornar ineficaz o quadro teórico proporcionado pelo filósofo moderno, o metafísico, e sua pretensão de estabilidade social pela razão, o que tornou a questão do conhecimento sua problemática por excelência:

Quando este metadiscurso recorre explicitamente a algum grande relato, como a dialética do espírito, a hermenêutica do sentido, a emancipação do sujeito racional ou trabalhador, o desenvolvimento da riqueza, decide-se chamar "moderna" a ciência que a isto se refere para se legitimar. É assim, por exemplo, que a regra do consenso entre o remetente e destinatário de um enunciado com valor de verdade será tida como aceitável, se ela se inscreve na perspectiva de uma unanimidade possível das mentalidades racionais: foi este o relato das Luzes, onde o herói do saber trabalha por um bom fim ético-político, a paz universal. [...] A função narrativa perde seus atores, os grandes heróis, os grandes perigos, os grandes périplos e o grande objetivo. Ela se dispersa em nuvens de elementos de linguagem narrativos, mas também denotativos, prescritivos, descritivos etc., cada um veiculando consigo validades pragmáticas sui generis. Cada um de nós vive em muitas destas encruzilhadas. Não formamos combinações de linguagem necessariamente estáveis, e as propriedades destas por nós formadas não são necessariamente comunicáveis. [...] Após os metarrelatos, onde se poderia encontrar a legitimidade? [...] $\mathrm{O}$ saber pós-moderno não é somente o instrumento de poderes. Ele aguça nossa sensibilidade para as diferenças e

\footnotetext{
${ }^{2}$ Apesar de concordarmos com Lyotard (1988), temos tido o cuidado de alertar para o fato de que as diversas teorias, das mais variadas escolas filosóficas modernas, apresentam como base as características por ele apontadas, em maior ou menor grau de adesão, aos conceitos e vocabulários considerados ineficazes pelas narrativas pós-modernas. Mas, para além desta base conceitual e do vocabulário referencial, há muitas diferenças, em maior ou menor superficialidade, maior ou menor idealização, entre as diferentes escolas filosóficas modernas no que diz respeito à recorrência a tais conceitos. Ou seja, temos defendido que, a despeito do grau de adesão, implícita ou explicitamente assumidos nas diversas teorias, os conceitos acima referidos podem ser apontados como conceitos estruturantes e paradigmáticos do vocabulário e do pensamento moderno.
} 
reforça nossa capacidade de suportar o incomensurável. Ele mesmo não encontra sua razão de ser na homologia dos experts, mas na paralogia dos inventores. (LYOTARD, 1998, p. XV-XVII)

À visão niilista e, em alguma medida, pessimista de Lyotard, corresponde uma característica marcante da pós-modernidade com a qual temos coadunado: a crise da legitimidade é muito mais uma crise dos pressupostos de verdade, da tentativa de referenciálos de modo internalista ao próprio metadiscurso, do que do seu conteúdo em si. Temos defendido que tais teorizações, a medida que denunciam toda tentativa expansionista de discursos auto referenciados porque supostamente neutros, têm inestimável valor político. Isto é, seu valor político reside justamente na denúncia de discursos que se apresentam como “discursos-mestres" (PETERS, 2000) cuja supremacia cultural está supostamente garantida pela sua capacidade de se transportar a todo e qualquer contexto, requerendo validade pragmática universalista, e minando com as demandas da diferença, seja ela cultural, ideológica, política ou filosófica. Vattimo (2007), por sua vez, parte pra pensar a Pósmodernidade a partir da relação que liga as reflexões nietzschianas e heideggerianas defendendo que, pensar com e a partir deles, significa distanciar-se da cultura superacionista da crítica que marcou a Modernidade:

Eles [Nietzsche e Heidegger] se acham, assim, por um lado, na condição de terem de distanciar-se criticamente do pensamento ocidental enquanto pensamento do fundamento; de outro, porém, não podem criticar esse pensamento em nome de uma outra fundação, mais verdadeira. É nisso que, a justo título, podem ser considerados os filósofos da pós-modernidade. O pós de pós-moderno indica, com efeito, uma despedida da modernidade, que, na medida em que quer fugir das suas lógicas de desenvolvimento, ou seja, sobretudo da idéia da "superação" crítica em direção a uma nova fundação, busca precisamente o que Nietzsche e Heidegger procuraram em sua peculiar relação "crítica" com o pensamento ocidental. (VATTIMO, 2007, p. VI-VII)

De acordo com Vattimo (2007), as reflexões nietzschianas e heideggerianas em relação aos fundamentos e valores supremos convidam-nos a experienciar o fim da perspectiva finalizada e monótona da história: "um convite a profanar as histórias unitárias, as histórias dos vencedores, enfim, questionar as histórias assépticas que põem em funcionamento a teleologia e o finalismo em favor da perpetuação da lógica progressista" (PIMENTEL-JÚNIOR; CARVALHO, 2014):

A pura e simples consciência - ou pretensão - de representar uma novidade na história, uma figura nova e diferente na fenomenologia do espírito, 
colocaria de fato o pós-moderno na linha da modernidade, em que domina a categoria de novidade e de superação. No entanto, as coisas mudam se, como parece deva-se reconhecer, o pós-moderno se caracterizar não apenas como novidade com relação ao moderno, mas também como dissolução da categoria do novo, como experiência de "fim da história", mais do que como apresentação de uma etapa diferente, mais evoluída ou mais retrógrada, não importa, da própria história. [...] A aplicação dos instrumentos de análise da retórica à historiografia mostrou que, no fundo, a imagem da história que nós temos é toda ela condicionada pelas regras de um gênero literário. Em suma, que a história é muito mais uma "estória", um relato, do que geralmente se está disposto a admitir. (VATTIMO, 2007, p. IX-XIV)

"Em outras palavras, a história universal torna-se impossível: uma história atravessada pela busca de causas últimas que comumente são dissolvidas, assim como os personagens criados para seus heróis.” (PIMENTEL-JÚNIOR; CARVALHO, 2014). A incorporação dessas teorizações no artigo nos leva a pensar em aceitar uma escola mais fraca, com objetivos mais modestos; uma escola que, sem ter a pretensão de formar indivíduos puramente "racionais", verdadeiros "senhores de si", dotados de conhecimentos que lhes permitem determinar os rumos da história, permita-se vivenciar a verdade de modo mais fraco, mais fabulizado. Nessa direção, as abordagens pós-modernas aqui trabalhadas, sobretudo o pensamento de Vattimo (2007), ultrapassam, não subvertem ou transgridem - sob o risco de ficar preso num paralelismo ou numa negação que reafirma a identidade do outro -, as abordagens modernas no sentido de produzir algo diferente, de inventar, de ousar outras narrativas e vocabulários, outros modos de contar o mundo e, por extensão, a escola. A característica de tal ultrapassagem, sempre precária e contingente porque mediada pela linguagem, poderia ser resumida pelas palavras de Santos (2006), a despeito das peculiaridades encontradas no modo como cada autor trabalhado descreve a pósmodernidade:

Crítica do universalismo e das grandes narrativas sobre a unilinearidade da história traduzida em conceitos como progresso, desenvolvimento ou modernização que funcionam como totalidades hierárquicas; renúncia a projetos coletivos de transformação social, sendo a emancipação social considerada como um mito sem consistência; celebração, por vezes melancólica, do fim da utopia, do ceticismo na política e da paródia na estética; concepção da crítica como desconstrução; relativismo ou sincretismo cultural; ênfase na fragmentação, nas margens ou periferias, na heterogeneidade e na pluralidade (das diferenças, dos agentes, das subjetividades); epistemologia construtivista, não-fundacionalista e antiessencialista. (SANTOS, 2006, p.29) 
É a partir dessas provoca-ações que partirmos para pensar o papel da escola. Adotando tais posturas e perspectivas para pensar o processo social de escolarização, pretendemos apenas ampliar o debate sobre o papel desta instituição sem a pretensão esgotar as possibilidades discursivas do mesmo, deixando de lado as perspectivas petrificantes: definitivamente, consideramos que esta é "uma discussão que não deveria trilhar os caminhos do que gosto de chamar de cultura do ou [...]" (CARVALHO, 2001, p.10), ou seja, dicotômico, excludente, que, em nome do fundamento, exige a escolha de um único caminho. Coloquemos em suspensão o mundo dicotômico, os fardos insustentáveis, as ambições totalizantes nas narrativas e entreguemo-nos à saborosa embriaguez labiríntica das incertezas! Inspirados em Rorty (2007), cuja linha de pensamento nos afasta de qualquer pretensão fundacionista, assumimos nossos posicionamentos aqui expressos como "uma disputa entre um vocabulário arraigado, que se transformou num incômodo, e um novo vocabulário, parcialmente formado, que traz a vaga promessa de coisas grandiosas” (RORTY, 2007, p. 34).

Em consonância com estes ares pós-modernos e pós-fundacionais, podemos dizer que nem o passado, entendido saudosamente como o "fundamento-mestre" (PETERS, 2000; RORTY, 2007) de uma moral/costumes/práticas simbólicas escolares "perdidas" no tempo, nem o futuro, entendido utopicamente como lugar onírico privilegiado a partir do qual ditamos o caminho "necessário", o dever ser, das práticas simbólicas escolares para que atinjam o status ideal, servem mais como referências privilegiadas - fora do tempo, do espaço e do acaso - das certezas do caminho. Desacreditando nos pensamentos erigidos a partir da lógica saudosista-utópica, que expressam "rotas de fuga" históricas em relação ao presente cuja base argumentativa repousa em fundamentos que minam com as demandas diferença e do devir histórico, temos defendido: "somente o presente vivido, aqui e agora, com outros, importa.” (MAFFESOLI, 2005, p.15). É justamente problematizando os efeitos potencialmente essencialistas e moralistas presentes nestes tipos de narrativas sobre o papel escolar, tão comum na literatura educacional, que pretendemos avançar numa compreensão pós-moderna do papel da escola na contemporaneidade, uma compreensão que reivindica a dimensão do tempo, do espaço e do acaso em direção a uma leitura pós-metafísica, além de um tratamento menos teleológico e mecânico (PRIGOGINE, 1996), dos rumos históricos desta instituição social. Discutiremos, a seguir, o que temos compreendido e denominado "rotas de fuga" presentes na escola atual e, a seguir, adentramos em algumas delas a partir dos seguintes subitens: a fuga para trás e a "invasão" das informações, discutindo o desejo de controle pela evocação do passado; e a fuga para frente e a escola poderosa, discutindo o 
desejo de controle pelo apelo ao futuro. Por fim, avançamos em torno da defesa de uma escola fraca.

\section{A escola atual e as "rotas de fuga"}

Talvez a tarefa mais difícil, se não impossível, seja definir as características que marcam uma determinada época. Talvez o problema seja mesmo o próprio processo de definição; o que nos leva a ter em mente que, qualquer levantamento das características de nossa época que fizermos será fruto de leituras já perspectivadas da realidade circundante: vivemos numa dinâmica espaço-temporal incerta, descontínua que vem, definitivamente, redimensionando o papel dos valores morais, das questões culturais, da política, do acaso, da mass mídia, enfim, dos ideais e instituições sociais que regem a vida cotidiana. De certa forma, era de se esperar que a escola, por se tratar da "instituição socialmente responsabilizada pela democratização da informação científica, na perspectiva de que esta se transforme em conhecimento pessoal de indivíduos sociais, compreendidos como sujeitos do conhecimento, pela agregação de significados relevantes à formação da cidadania.” (FRÓESBURNHAM, 2002, p.2), acompanhasse tais mudanças.

No entanto, ao invés de aceitar o caráter incerto e transitório inerente aos complexos processos sociais, a ideia soberana, e talvez superficial, é a de que a escola, malgrado todas as considerações acerca das rápidas e efervescentes mudanças no cenário social, sofre de um relativo atraso frente às mesmas; mudanças e convulsões sociais estas que continuam acontecendo e vêm provocando profundos questionamentos sobre o papel da escola e da educação na contemporaneidade. Questionamentos estes que vem colocando tanto o estatuto social da profissão professor como a escola no "olho do furacão" e exigindo configurações distintas para ambos.

De acordo com tais colocações, inferimos que, de um lado, há o reconhecimento da saturação da lógica que tradicionalmente rege os espaços escolares expresso pela constante insatisfação social e, por outro lado, há o não saber lidar com a não-resposta própria dos processos incertos. Acontece que, por não estar nem cumprindo seu suposto papel salvacionista e nem mesmo estar acompanhando as incessantes convulsões sociais, tensões entre o campo social e o trabalho docente têm sido estabelecidas com freqüência e minando fortemente a instituição escola. 
Diante disso, é possível constatar que são tensões estabelecidas, em parte, devido à crença de que a relação entre a sociedade e a escola funciona numa dinâmica linear do tipo "demanda social - resposta da escola", como se fosse possível tanto extirpar mecanicamente a escola da sociedade, como prever de forma tão clara e reversível os rumos que a sociedade e, por extensão, a instituição escolar, devem tomar ao longo de sua história:

E que tal a argumentação do materialismo histórico, insistindo em que o desenvolvimento da ciência poderia ser representado, em cada passo, como uma resposta a necessidades sociais? Considere-se a teoria largamente difundida de que a obra de Newton sobre a gravitação surgiu por causa dos interesses marítimos em expansão da Grã-Bretanha. Os que esposam tal teoria não tentam nada para descobrir interesses marítimos que tivessem estimulado o polonês Copérnico em Heilsberg, ou o alemão Kepler em Praga, ou o florentino Galileu a laborar, um século antes de Newton, no estabelecimento das fundações do seu trabalho. Não dão também qualquer atenção à grandiosa resposta dada a Newton por países como a Suíça e a Prússia, nem um pouco interessados em problemas marítimos. Influenciados por avassalador preconceito materialista, eles nunca tentaram aplicar até mesmo as regras mais elementares do pensamento crítico. (POLANYI, 2003, p.133)

Ou seja, a partir disso, temos a impressão de que é possível constatar que a ideia que habita fortemente o imaginário social é que cada passo dado pela escola deve progredir em direção à resolução das demandas impostas pela sociedade a fim de garantir o bem-estar social. Tal pensamento, ao conferir um tratamento mecânico e "purificador" à própria história, acaba por tornar-se um vocabulário potencialmente moralista e mecânico, pois confere ao social o controle das práticas simbólicas de escolarização. Temos a impressão que esse pensamento instrumentalista tem culminado em consequências desastrosas que expressam o quanto uma sociedade centrada em valores fortes pode ser destrutiva em relação àquelas instituições que perseguem objetivos próprios e com fim em si mesmo, construídos de acordo com circunstâncias históricas contingentes. As palavras de Foucault ajudam-nos a melhor caracterizar tal forma de pensamento e sua pretensão de planificar a história, de reduzi-la a finalidades monótonas:

Paul Ree se engana, como os ingleses, ao descrever gêneses lineares - ao ordenar, por exemplo, toda a história da moral apenas através da preocupação com o útil: como se as palavras tivessem guardado seu sentido; os desejos, sua direção; as ideias, sua lógica; como se esse mundo das coisas ditas e desejadas não tivesse conhecido invasões, lutas, rapinas, disfarces, artimanhas. [...] De fato, o que Nietzsche não parou de criticar, [...] é essa forma de história que reintroduz (e supõe sempre) o ponto de vista suprahistórico: uma história que teria por função recolher, em uma totalidade bem 
fechada em si mesma, a diversidade finalmente reduzida do tempo; uma história que permitiria nos reconhecermos em todo lugar e dar a todos os deslocamentos passados a forma da reconciliação; uma história que lançaria sobre o que está atrás dela um olhar de fim do mundo. Essa constrói para si um ponto de apoio fora do tempo; [...] isso porque ela supôs uma verdade eterna, uma alma que não morre, uma consciência sempre idêntica a si mesma. (FOUCAULT, 2008, p.260-271)

Em paralelo às crenças nas rotas de fuga guiadas por linhas de pensamento fincadas num futuro utópico, temos, também, os que acreditam que a escola segue uma rota de colapso. Ao mudar determinados valores em relação à escola do passado, segue uma rota de perdição tão evidente nos dias atuais. Tal postura fica evidente, por exemplo, quando analisamos a evolução das tecnologias da informação e comunicação, a velocidade de informações circulantes e simultaneamente as resistências sofridas por estas tecnologias na sociedade. A escola, por não ter como se defender, protege-se num conservadorismo desmedido e potencialmente mortífero na medida em que se fecha aos debates externos que vêm sendo travados no campo da educação. A sociedade, por não saber lidar com a nãoresposta imediata, põe em xeque a instituição escolar através da devastação do ensino público socialmente referenciado e de qualidade.

Temos defendido que ambas são formas essencialistas de pensamento, que, baseadas em um colecionismo conservador e/ou utópico, buscam fixar a identidade escolar. Ambas as formas de pensamento serão discutidas a seguir sabendo que, simultaneamente ao descrevêlas, ficará evidente suas incompatibilidades tanto com o pensamento que rege a escola quanto à dinâmica irreversível e imprevisível inerente aos processos históricos e sociais.

\section{A fuga para trás e a "invasão" das informações}

Para os conservadores saudosistas, a escola vem perdendo o brilho, já que não temos mais a escola e os alunos de antigamente. Neste caso, tudo deve voltar a ser como antes: os alunos devem ter o mesmo comportamento dos de antes, voltar a aprender e se comportarem socialmente como os de outrora, já que forneciam um bom exemplo de turma ideal. Podemos constatar uma potência nociva desta rota de fuga através de um conflito fruto do entendimento da tecnologia como desumanizadora. $\mathrm{O}$ conflito surge com a recusa das TICs como possibilidade de (re)configuração do espaço escolar na perspectiva defendida por Levy:

As telecomunicações geraram esse novo dilúvio por conta da natureza exponencial, explosiva e caótica de seu crescimento. A quantidade bruta de 
dados disponíveis se multiplica e se acelera. A densidade dos links entre informações aumenta vertiginosamente nos bancos de dados, nos hipertextos e nas redes. Os contatos transversais entre os indivíduos proliferam de forma anárquica. É o transbordamento caótico das informações, a inundação dos dados, as águas tumultuosas e os turbilhões da comunicação, a cacofonia e o psitacismo ensurdecedor das mídias, a guerra das imagens, as propagandas e as contra-propagandas, a confusão dos espíritos. (LÉVY, 1999, p.13).

Diríamos que a fuga para trás é uma forma de recusa a este "dilúvio": fundamentandose socialmente em referências geo-históricas pré-TICs, os recursos tecnológicos assumem um aspecto invasivo, uma espécie de vírus que chega com o propósito de provocar perturbações no antigo equilíbrio escolar. Na contramão dessa rota de fuga, teorizações contemporâneas defendem a sociedade da informação. Comumente, fala-se que vivemos em tal, dado a ampliação dos loci de produção do conhecimento para além das universidades e dos centros de pesquisa bem como a descentralização e desconcentração dos meios de difusão deste conhecimento com o aumento expressivo do tráfego de informações via tecnologias da informação e comunicação (TIC). Esse contexto de acesso imediato e desierarquizado à informação, de verdadeiras revoluções dos espaços sócio-culturais operadas pelas TIC, não é visto de forma única, umas mais ingênuas, outras mais realistas. Lembremos os que põem em discussão se estamos mesmo em uma sociedade da informação:

[...] não importa como se considere uma sociedade da informação, uma coisa está faltando nesta metáfora: as pessoas. [...] é preciso uma ligação que nos possibilite construir nossos próprios sentidos a partir da informação, sob pena das pessoas se sentirem derrotadas pela pressão da tecnologia e da economia. (VAN DER ZEE, 1994, p.164 apud FRÓES-BURNHAM, 1999, p.297).

Independente das disputas travadas entre as metáforas na busca de uma melhor caracterização das mudanças sociais oportunizadas pelas TICs, um elemento comum está presente em todas elas: a própria presença das TICs e o caráter irreversível das ressonâncias provocadas pelas mesmas no espaço social, não há volta. Particularmente na educação, quanto a esta irreversibilidade podemos citar o descentramento da informação única e exclusivamente na figura do professor: a partir da exploração do mundo virtual, do campo de possibilidades que se abrem num território em rede, é possível pensar na formação pela pesquisa, baseada em práticas de ensino e aprendizagem voltados para a busca, análise e tratamento de informações que circulam no âmbito social de modo a fomentar tanto a curiosidade quanto a impassividade, uma postura investigativa inconformista: 
O sistema formal de educação [...] está experimentando uma invasão dessa cultura tecnológica, seja por uma pressão direta da indústria cultural, de equipamentos, de entretenimento e comunicação, seja pela pressão exercida pelos próprios alunos - crianças e jovens - que, pela convivência nesse mundo impregnado desses novos valores, levam para a escola todos os seus elementos. (PRETTO, 1996, p.102) (grifo nosso)

Para além da subordinação à uma racionalidade técnico-instrumental, a presença das TICs aprofunda a discussão sobre a própria natureza humana e a ampliação de suas potencialidades a partir da estruturação de novas práticas sociais numa linguagem em rede. Essas "novas" práticas significam apenas a incorporação das TICs na já existente rede de táticas e modos de fazer escola, e não a ideia de uma substituição, um abandono do antigo em relação ao "novo". Como dito, distanciamo-nos da lógica progressista:

A presença dessas tecnologias na sociedade e, consequentemente, nas escolas, não deve ser compreendida como mera atualização de métodos, como a introdução de modernas ferramentas para as velhas práticas educacionais. Em outras palavras, essas tecnologias não entram na escola como facilitadoras dos processos, mas como complicadoras das práticas pedagógicas, trazendo novos desafios para os processos de ensino e de aprendizagem [grifo dos autores]. (PRETTO; LIMA JÚNIOR, 2005, p.208)

Não se trata, portanto, de fazer a mesma educação que sempre se fez, agora com o acréscimo de uma nova tecnologia. Trata-se de fazer uma "educação outra" levando em consideração as mudanças que as tecnologias provocam na cultura, na sociedade, no sujeito, na linguagem, nas formas de pensar e construir conhecimento. Também não se trata de uma simples substituição do antigo pelo novo. Enquanto as redes digitais rearticulam, reestruturam, transformam as formas de pensamento e linguagem utilizadas até então, dando a elas novas e amplas dimensões, cabe à escola articular esse novo estilo aos antigos, sem, no entanto, substituí-los. (BONILLA, 2005, p.12-13)

Se considerarmos que todas as experiências humanas podem nos falar alguma coisa, não faz mais sentido sustentar a substituição progressista das velhas práticas pelas "máquinas super modernas", muito menos o enrijecimento identitário petrificante que a escola defende ao se enclausurar em suas conchas ouriçadas. São precisamente as clausuras identitárias de fundo essencialista que vimos questionando em nossos trabalhos. Tais posturas, coadunadas com a lógica moderna superacionista - seja ela para trás ou para frente - acabam por demonstrar apenas a gigantesca falta de entendimento quanto à irredutibilidade e a singularidade de cada uma das experiências humanas. Pensar essas experiências a partir de uma perspectiva em rede, em paralelo, sem hierarquias, torna cada experiência insubstituível 
num sentido imanente e diferente em si mesmo do termo uma vez que proporcionam e ampliam nossas referências de mundo sem destruir as até então experimentadas.

\section{A fuga para frente e a escola poderosa}

Para os sonhadores futuristas, a escola é a instituição responsável pela transformação social a partir da formação dos alunos que serão responsáveis pela futura geração do país. Em alguns casos, essas posturas, calcadas numa perspectiva finalizada da história, se apresentam, também, a partir de anseios fortemente conservadores, o que complexifica ainda mais nosso trabalho de análise dessas diferentes posturas que, muitas vezes, habitam uma mesma discussão. No entanto, de modo geral, essas posturas são atravessadas pela ideia de que é necessário formar indivíduos fortes, extremamente racionais através de conhecimentos que não podem demonstrar qualquer sinal de fraqueza ou incerteza. Os estudos que seguem a linha histórico-crítica do currículo e dos saberes escolares podem auxiliar e reforçar as constatações de que o melhor saber é aquele que, criticamente, possibilita ao indivíduo superar a condição ignorante inicial e progredir em direção a uma formação que dignifica o sujeito para viver em sociedade. Enfim, trata-se de tentativas e controle identitário tanto escolar, como das pessoas que a habitam, por formas de conhecimento tidas como poderosas e independentes de contexto.

Para Forquin (1992), é essa uma visão naturalizada que pode ser refutada. Tanto o processo de seleção cultural feito pela escola como o de legitimação de determinados saberes em detrimento de outros no currículo escolar são pontos passíveis de serem explorados a partir do estudo da história das disciplinas escolares, território de conflitos, negociações e disputa por espaço. Para ele, essas discussões contribuem para a "desnaturalização" dos modos de conceber o currículo escolar:

O próprio de uma reflexão sociológica ou histórica sobre os saberes escolares é contribuir para dissolver esta percepção natural das coisas, ao mostrar como os conteúdos e os modos de programação didática dos saberes escolares se inscrevem, de um lado, na configuração de um campo escolar caracterizado pela existência de imperativos funcionais específicos (conflitos de interesses corporativos, disputas de fronteiras entre as disciplinas, lutas pela conquista da autonomia ou da hegemonia no que concerne ao controle do currículo), de outro lado na configuração de um campo social caracterizado pela coexistência de grupos sociais com interesses divergentes e com postulações ideológicas e culturais heterogêneas, para os quais a escolarização constitui um trunfo social, político e simbólico. (FORQUIN, 1992, p. 43-44) 
Nesses moldes escolares permeados por ideologias e luta por poder, consideraremos que a escola se torna responsável pela veiculação do conhecimento poderoso, o que podemos chamar de uma escola crítica. Seguindo a linha dos estudos críticos do currículo escolar e dos processos de escolarização, encontra-se Young (2007). Em artigo seminal intitulado Para que servem as escolas? Young (2007) defende a ideia de que o papel da escola é transmitir "conhecimento poderoso", um conhecimento que permita aos alunos - sobretudo os mais desfavorecidos socialmente - pelo menos intelectualmente, caminharem para além de suas circunstâncias locais e particulares. Nessa direção, defende que o conhecimento adquirido na escola, pelo menos potencialmente, é o conhecimento independente de contexto, ou seja, um conhecimento desenvolvido para fornecer generalizações e buscar a universalidade; tal conhecimento fornece uma base forte para se fazer julgamentos que é, geralmente, mas não unicamente, relacionado às ciências. Nesse sentido, essa é a escola que, ensinando o conhecimento independente de contexto, dará poderes aos indivíduos para transformar a sociedade e ditar os rumos históricos.

De acordo com tal perspectiva crítica, os conhecimentos que devem ser ensinados na escola são os que dão consciência plena ao indivíduo. Recusar o ensino deste tipo de conhecimento é visto como falta de vontade e compromisso político ou como medo de que, uma vez tendo adquirido a verdadeira consciência através do conhecimento poderoso, o indivíduo possa desmantelar as instituições socialmente estabelecidas - incluindo a escola - e aprovadas, dado que regidas por interesses obscuros e particulares com fins de perpetuar determinada tradição inventada:

Inclui tanto tradições realmente inventadas, construídas e formalmente instituídas, quanto tradições que emergem de forma menos definível dentro de um período de tempo breve e datável - coisa talvez de alguns anos - e que se estabelecem com grande rapidez. [...] Tradição inventada significa um conjunto de práticas e ritos: práticas, normalmente regidas por normas expressas ou tacitamente aceitas; ritos - ou natureza simbólica - que procuram fazer circular certos valores e normas de comportamento mediante repetição, que implica, automaticamente, em continuidade com o passado. De fato, onde é possível, o que tais práticas e ritos normalmente buscam é estabelecer a continuidade com um passado histórico apropriado. (HOBSBAWN, 1985 apud GOODSON, 2008, p.112)

\footnotetext{
${ }^{3}$ Para Young (2007, p.1294), esse conhecimento não se refere a quem tem mais acesso ao conhecimento ou quem o legitima, embora reconheça a importância de ambas as questões. Para ele, este conhecimento refere-se ao que o conhecimento pode fazer, como, por exemplo, fornecer explicações confiáveis ou novas formas de se pensar a respeito do mundo, um conhecimento que não é disponível em casa. Defende ainda que, nas sociedades modernas, este conhecimento é cada vez mais o conhecimento especializado, o conhecimento científico.
} 
Ainda na linha crítica, para Goodson (2008), começar qualquer análise dos processos de escolarização bem como dos seus modos de estruturação sem questionar - ou seja, como um pressuposto - uma forma e um conteúdo de currículo debatido e concluído em situações históricas particulares e com base em outras prioridades sociopolíticas, é privar-se de toda uma série de entendimentos e insights em relação aos aspectos de controle e operação da escola e sala de aula; é assumir as mistificações de episódios anteriores de governo como dados incontestáveis. Para ele, o valor principal destas investigações de cunho histórico a respeito das disciplinas escolares reside, sobretudo, em uma capacidade de investigar a realidade interna e a autonomia relativa da escolarização, ou seja, procurar compreender os mecanismos de estruturação dos conhecimentos escolares, a transformação dos saberes em conhecimento escolar, as predominâncias e tendências nos modos de estruturação dos conteúdos e métodos de ensino em determinado período histórico.

De acordo com os estudiosos dessa linha, a grande contribuição que o estudo da história do currículo e das disciplinas escolares apresenta é a possibilidade destes “desnaturalizarem" os conhecimentos presentes na escola e permitirem a superação de um currículo que, até então, transmite conhecimentos irrelevantes sócio-economicamente, e passe a ensinar conhecimento poderoso. Para os teóricos desta linha, é condição fundamental a desmistificação deste currículo escolar insignificante ao esclarecer que ele está imerso na história e, consequentemente, sujeito às mudanças e flutuações impostas pelas demandas sociais que, neste caso, são indiscutivelmente claras e, portanto, devem ser perseguidas pela escola. Apostam que tais atitudes culminarão na ruptura de um passado histórico, que comumente é visto como permeado por interesses particulares da classe poderosa em se manter no poder, em direção ao progresso social. Ou seja, apesar de velada pelos interesses dos poderosos, é possível acessar e transmitir o conhecimento verdadeiro e poderoso, o fundamento, que possibilitará a transformação social a favor da sociedade perfeita.

Contrapondo tal visão, as palavras de Maffesoli são esclarecedoras: "O progresso heroico, próprio do modelo judaico-cristão, depois moderno, repousava sobre a concepção do indivíduo ativo, senhor de sí, dominando a si mesmo e a natureza.” (MAFFESOLI, 2005, p.99). Temos afirmado que a escola pensada desta forma é a escola regida pelo "princípio do logos” (MAFFESOLI, 2005, p.98), uma escola iluminista que aposta excessivamente na razão mecânica e predizível, instrumental e utilitária como alavanca propulsora que retira a pessoa da condição animal e eleva-o à posição de indivíduo, senhor de si, seguro dos seus preconceitos e de sua verdade imutável porque racional e objetiva; uma verdade que, na 
medida em que comporta um caráter fortemente teleológico, acaba transfigurando a identidade tanto do sujeito como escolar em rocha, já que continua a não ter dúvidas sobre seu verdadeiro papel de ditar as transformações sociais necessárias para atingir o futuro ideal.

Apesar de concordarmos em parte com as teorias críticas, sobretudo quando trazem à luz a possibilidade dos homens exercerem seus "podres poderes" sobre os próprios homens quando da aquisição de conhecimento poderoso, bem como quando trazem à tona as relações de poder que atravessam as questões curriculares, questionamos: será que a dinâmica social funciona assim de modo tão sintético e linear? Será que o conhecimento poderoso é plena e linearmente compreensível como se deseja? Será que as tentativas de ordenação dos sentidos e da educação, pelo conhecimento poderoso, estão atuando como um grund, um fundamento forte sobre o qual se julga poder ditar e instituir a verdade sobre a educação escolar? "O futuro é dado ou está em perpétua construção?”(PRIGOGINE, 1996, p. 9)

Temos a impressão que o mais estarrecedor para os que estão imbuídos do espírito futurista e progressistas da fuga para frente, pode ser o reconhecimento de que a escola pode não ser mais a instituição garantidora de ascensão social e lucidez total do indivíduo, pode não ser mais a forte instituição que humaniza o sujeito, enfim, pode não ser mais a forte instituição que controla as identidades e a educação pelo conhecimento plenamente racional. Com base nisso, temos defendido que pode estar na hora de nós assumirmos que o inferno da escola pode não ser mais o outro que me impede de atingir o futuro através da privação do poder e do conhecimento poderoso, dado que a própria linguagem é contingente, é precária e provisória, sendo a educação, portanto, parte dessa dinâmica complexa e imprevisível na qual o imponderável, o acaso e as erosões de sentidos têm assento, quer queiramos ou não.

\section{Constatações}

Em nossas discussões, temos partido da compreensão das rotas de fuga como escapismos que não encaram o presente fugindo para trás ou para frente. Ambas são posturas que, em nome das certezas que vislumbram para se atingir a escola ideal, tratam a história de modo determinista e reversível, tentando fixar a identidade escolar e eliminar a diferença por meio de argumentos fundacionistas calcados em colecionismos essencialistas. Ambas as formas estão, no fundo, conectadas pela superação da escola do presente, seja através da fuga para trás ou fuga para frente, a fim de promover o bem estar onírico a partir de uma escola que atenda as demandas sociais, isto é, a subordinação da formação e da identidade escolar a 
uma dada racionalidade instrumental. Nesse sentido, quando a escola foge do que podemos chamar de superação como destino, ou seja, não se permite este tipo de tratamento idealizado e escapa a estas fugas, é vista como mergulhada em obscurantismo e futilidades. Por sua vez, à medida que estas crenças da superação vão habitando cada vez e com mais força o imaginário social, é atestado que o locus da escola se encontra eclipsado por objetivos enigmáticos e escusos, dado que tais crenças distorcem e põem em xeque o autofuncionamento da escola em nome de supostas demandas sociais que, segundo os que aderem a este tipo de pensamento, estão sempre muito claras, cabendo, assim, à sociedade mostrá-las e impô-las à escola.

A partir de nossos estudos, temos defendido que a sociedade pode não se comportar de modo tão simétrico e perfeito, isto é, as dinâmicas sociais, constituídas e marcadas por eventos de linguagem, não comportam tratamentos essencialistas e peremptórios que permanecem tentando minar o acaso, a contingência e o aspecto provisório das formas de socialidade. Isto é, “a irreversibilidade [e a incerteza da/na linguagem] não pode mais ser identificada como uma mera aparência que desapareceria se tivéssemos acesso a um conhecimento perfeito." (PRIGOGINE, 1996, p. 11). Em Prigogine, temos encontrado algumas palavras que reforçam nossas posições:

A formulação das "leis da natureza" trouxe um elemento crucial a este debate antigo. De fato, as leis enunciadas pela física não têm como objetivo negar o devir em nome da verdade do ser. Muito pelo contrário, elas visam a descrever a mudança, os movimentos caracterizados por uma velocidade que varia ao longo do tempo. E, no entanto, seu enunciado constitui um triunfo do ser sobre o devir. O exemplo por excelência é a lei de Newton, que liga a força à aceleração: é ao mesmo tempo determinista e reversível no tempo. Se conhecemos as condições iniciais de um sistema submetido a essa lei, ou seja, seu estado num instante qualquer, podemos calcular todos os estados seguintes, bem como todos os estados precedentes. Mais ainda, passado e futuro desempenham o mesmo papel, pois a lei é invariante em relação à inversão dos tempos t- -t. A lei de Newton justifica bem, portanto, o famoso demônio de Laplace, capaz de observar o estado presente do universo e dele deduzir toda a evolução futura. [...] As leis da natureza enunciadas pela física são da esfera, portanto, de um conhecimento ideal que alcança a certeza. [...] Se permutarmos o futuro, ou seja "+t", com o passado, ou seja, “-t”, obteremos um movimento pendular tão plausível quanto o primeiro. [...] Os processos reversíveis correspondem sempre a idealizações. (PRIGOGINE, 1996, p. 19-25)

Temos defendido que as diferentes aparências das rotas de fuga são posturas, portanto, permeadas por idealizações - caso a escola fosse como antes, ou seja, “-t”, ou caso a escola venha a ensinar o conhecimento poderoso, ou seja, "+t", - dado que retiram mecanicamente 
uma infinidade de "variáveis" do meio e dão um tratamento perfeitamente reversível à escola, como se esta pudesse, de fato, estar isolada do meio social e comportasse tal tipo de tratamento sem variáveis. À sociedade, de um modo geral através deste pensamento, é conferido um tratamento exclusivamente mecânico e teleológico. Convém, portanto, questionar este desejo de desalienamento que deve ser perseguido pela escola. Tal pensamento culminou na perda de evidência do papel social que a escola historicamente vem sofrendo, a ponto de questionamentos do tipo "Pra que escola?" e/ou "Pra que professor?" serem constantemente proferidos através de situações diversas.

Tentando seguir linha de pensamento distinta, temos defendido que é parte dos eventos lingüísticos a variação, o excesso que escapa, a erosão de sentidos, a irreversibilidade. (LYOTARD, 1988; PETERS, 2000; MAFFESOI, 2005). Inspirados em Maffesoli (2005), temos anunciado a morte da ESCOLA - e o maiúsculo é proposital -, para fins de oxigenação do sentimento que nos anima a pensar em modos distintos de organização deste espaço para além do mero utilitarismo e/ou criticismo, de achar que a escola é um troço útil pra que a gente, depois de sair dela, possa se virar na sociedade, como se a mesma estivesse realmente fora do campo social e/ou servisse a interesses utilitaristas tão claramente dados.

Reconhecendo que a escola passou de um contexto de promessa e salvação das barbáries sociais para um contexto de incertezas, no qual pode não haver mais garantia de que, tendo uma vez estado nela, se ascenderá socialmente com a consciência certa dos caminhos a seguir, acreditamos que à pergunta Pra quê escola?, de caráter fortemente instrumentalista e pragmático, associa-se, no momento atual, uma resposta ainda mais inquietante: pode não haver resposta imediata. A escola, de fato, tem perdido seu papel social a ponto de as pessoas perguntarem se realmente vale a pena manter essa instituição, o que fica evidente com a recente defesa do homeschooling no Brasil, país onde educação é direito e dever do Estado. No entanto, mesmo diante desta perda de evidência, isso não tem impedido de reconhecer que, aliado ao projeto da modernidade, o excesso de luz que tanto governou e tem tentado governar a escola, acabou escurecendo-a em alguma medida, contribuindo assim para sua própria saturação: "Temos que formar cidadãos plenamente autônomos!" "Temos que formar dignamente a geração que vai ser responsável pelo futuro do país!", frases, notadamente escapistas, que ressoaram e tem ressoado com tal força no espaço escolar que acabaram por desencadear verdadeiras corridas atrás de fórmulas - muitas das quais, diga-se de passagem, tendo ainda como base de apoio o racionalismo moderno, atualizaramse freneticamente através de mais e mais disciplinas no currículo escolar! - que pudessem 
fazer o estudante atingir um estado pleno de autonomia, uma identidade permanente, um ponto que, uma vez atingido, torná-lo-ia sujeito digno de viver na sociedade. Temos encarado, por exemplo, as ações governamentais em torno da fixação de uma Base Nacional Comum Curricular como uma dessas tentativas de eliminar o imponderável e a diferença nos processos educativos, e iluminar o espaço escolar com conhecimento poderoso capaz de fixar as identidades.

Diante das inquietantes constatações cotidianas de que pode não haver resposta imediata, como também da impossibilidade de alcance, via escola, de um estado plenamente autônomo e absoluto da identidade do sujeito, convém reconhecer que isso não tem impedido operar, dentro do campo das possibilidades pensadas - já que estas não encerram em si todas as virtualidades da potência que a alimenta, trazendo, de acordo com o devir histórico, ao plano do pensado novas possibilidades que, em determinado instante, ainda não estivessem disponíveis ao mesmo -, atualiza-ações distintas com vistas a novos meios de organização do espaço escolar. Em nossas atualiza-ações, temos, sobretudo, questionado o potencial do vocabulário moderno cujos efeitos e apostas pouco evidentes deixam ver sinais de esgotamento heurístico e saturação no campo educacional.

Trata-se, portanto, de reconhecer a dualidade e a ambivalência das apostas humanas: ao passo que reconhecemos a saturação da lógica moderna na regência escolar, continuamos, em alguma medida, apostando nesta instituição e buscando, intuitiva e cotidianamente, novos sentidos de organização e narração da mesma. Resta reconhecer que, dado o próprio convite à sedimentação e funcionamento desses novos sentidos, haverá sempre, em algum espaço/tempo, a emergência de anomalias, de situações que possam não se dobrar a estes novos sentidos e que, portanto, representarão simultaneamente suas limitações e, sobretudo, seu caráter de produção humana, dado que assumimos neste trabalho a ideia de que "uma teoria completa e definitiva é quimérica e mistificadora.” (CASTORIADIS, 1982, p.89). Desta forma, "reis vão se sucedendo no labirinto irreversível do caminhar histórico." (CARVALHO, 2001).

Temos apostado na noção de ingresso (MAFFESOLI, 2005) para nos auxiliar na compreensão da escola como uma instituição que persegue seus próprios objetivos com fins em si mesmos, notadamente, objetivos mais modestos. Inspirados nesta noção, temos afirmado que, ao invés de progredir e ascender identitária e socialmente tendo uma vez estado na escola - o que condiciona e determina um fim externo à própria escola como se esta pudesse controlar o futuro - a pessoa ingressa no espaço escolar, ou seja, entra sem 
progredir ${ }^{4}$. Uma noção similar à de ingresso que talvez ilustre bem o que queremos dizer é a de flecha do tempo de Prigogine (1996). Para ele, a flecha do tempo está associada à ocorrência dos processos irreversíveis na natureza, à ocorrência de processos que não mais se assenta em certezas, mas avança sobre possibilidades. E, ao avançar sobre possibilidades, a flecha do tempo simultaneamente desempenha um papel construtivo, gerador de ordem, mostrando que "a vida só é possível num universo longe do equilíbrio.” (PRIGOGINE, 1996, p.29-30).

Uma noção que pode reforçar ainda mais os argumentos defendidos acima, ainda de acordo com Prigogine, é o de atualização de possibilidades. Se, por um lado, consideramos a escola a instituição socialmente eleita para difusão do conhecimento científico (FRÓESBURNHAM, 2002) e, por outro lado, temos que a ciência já não pode mais se identificar com certeza (PRIGOGINE, 1996), e está sempre atualizando possibilidades que emergem a partir do seu próprio auto-funcionamento, convém assumir que, apesar de ser um bom caminho, a escola pode não ser exclusivamente o meio através do qual a pessoa garanta ascensão social e conhecimento poderoso capaz de fixar sua identidade. Ao ingressar na escola, portanto, pode não haver, tal como sempre almejou o projeto moderno de formação racionalista, trajetórias e certezas pré-definidas que garantam, através de fórmulas mágicas, a educação plena e de qualidade. Talvez, o X da questão seja: o que é mesmo que se considera por educação plena e de qualidade?

Convém, portanto, à sociedade possibilitar o auto-funcionamento da escola sem constrangimento - atualmente expresso, a nosso ver, (i) pela precarização e desvalorização contínua das condições de trabalho docente; (ii) pelas tentativas de fixação de bases comuns reduzindo o trabalho docente a um aplicacionismo empobrecedor; (iii) pelas tentativas de amordaçar os professores por meio de Projetos de Lei que proíbem falar sobre Evolução, Política e Gênero nas escolas ${ }^{5}$, etc. - e longe do equilíbrio, permitindo a esta seguir seus próprios objetivos e desafios que se apresentam ao longo do seu caminhar geo-histórico. Essas são constatações que apontam o quanto uma sociedade centrada em fortes valores estejam eles enraizados no passado ideal ou no futuro longínquo - pode ser potencialmente

\footnotetext{
${ }^{4}$ Temos recorrido à noção de ingresso como forma de pensar a experiência escolar, pois há nela uma forte desconfiança em relação às narrativas de subjetividade modernas centradas no progresso da razão, na formação do sujeito vigilante, progressivamente consciente e reflexivo. De acordo com Maffesoli, tratam-se de narrativas de subjetividade implicadas na realização do "sujeito pensante, autônomo, consciente, senhor de uma história individual a realizar e ator contratual de uma história coletiva em marcha" (MAFFESOLI, 2005, p. 163) que, a nosso ver, têm mostrado sinais de saturação.

${ }^{5}$ Ver, por exemplo, o Projeto de Lei Escola Sem Partido, PL 867/2015, e todos os projetos de lei a eles associados cujo foco prioritário tem sido a doutrinação e o esvaziamento político-epistemológico da Educação Básica.
} 
mortífera às suas próprias instituições, uma vez que àquelas - no caso deste trabalho, a escolar - cujos objetivos sejam apenas perseguir as questões de sua pertinência, será constantemente dado o desafio de nadar contra a corrente, postura notadamente incompatível com os princípios de uma sociedade supostamente livre. Diante dessas constatações, portanto, pode ser conveniente convidar a deixar de odiar a escola do presente, seja através da fuga para trás ou da fuga para frente, compreendendo-a e aceitando-a tal como ela é, uma escola com fundamentos fracos, precários e provisórios porque contingentes.

\section{Referências}

ANDREOTTI, Vanessa Oliveira. Conhecimento, escolarização, currículo e a vontade de "endireitar" a sociedade através da educação. Revista Teias, Rio de Janeiro, v. 14, n. 33, p. 215 - 227, Dossiê Especial, 2013.

BONILLA, Maria Helena Silveira. Escola aprendente: para além da sociedade da informação. Rio de Janeiro: Quartet, 2005.

CASTORIADIS, Cornelius. A instituição imaginária da sociedade. $2^{\mathrm{a}}$ ed., Rio de Janeiro: Paz e Terra, 1986.

CARVALHO, Maria Inez da Silva de Souza. Uma viagem pelos espaços educacionais do município de Santo Antônio de Jesus: possibilidades, atualizações, singularidades, transituações. 180f. Tese (Doutorado em Educação). Universidade Federal da Bahia, Bahia, Salvador, 2001. Orientadora: Prof $^{a}$ Dr $^{\mathrm{a}}$ Teresinha Fróes Burnham.

FOUCAULT, Michel. Nietzsche, a genealogia, a história. In: Ditos e escritos, II. $2^{\mathrm{a}}$ ed. Rio de Janeiro: Forense Universitária, 2008.

FRÓES BURNHAM, Teresinha. Complexidade, multirreferencialidade, subjetividade: três referências polêmicas para a compreensão do currículo escolar. Em Aberto. v.12, n. 58, p. 313, 1993.

FRÓES BURNHAM, Teresinha. Sociedade da informação, sociedade do conhecimento, sociedade da aprendizagem: implicações ético-políticas no limiar do século. In: Lídia Maria Batista Brandão, Nídia Linaert Lubisco. (Orgs.). Informação e informática. Salvador: Edufba, 1999, p. 283-306.

FRÓES BURNHAM, Teresinha. Análise Contrastiva: memória da construção de uma metodologia para investigar a tradução de conhecimento científico em conhecimento público. Datagramazero Revista de Ciência da Informação, www.dgz.org.br - rev eletrônic, v. 03, n. 3, 2002.

GOODSON, Ivor F. Currículo: teoria e história. Trad. Attílio Brunetta. 8.ed. Petrópolis: Vozes, 2008. 
LÉVY, Pierre. Cibercultura. Trad. Carlos Irineu da Costa. São Paulo: Ed. 34, 1999, 264p.

LYOTARD, Jean-François. O pós-moderno. $3^{\text {a }}$ ed. Rio de Janeiro: José Olympio Editora, 1988.

MAFFESOLI, Michel. A transfiguração do político: a tribalização do mundo. Trad. Juremir Machado da Silva. $3^{a}$ ed. Porto Alegre: Sulina, 2005. 230p.

MAFFESOLI, Michel. Elogio da razão sensível. 4. ed. Pretópolis: Vozes, 2008.

PETERS, Michael. Pós-estruturalismo e filosofia da diferença. Trad. Tomaz Tadeu da Silva. Belo Horizonte: Autêntica, 2000.

PIMENTEL-JÚNIOR, Clívio; CARVALHO, Maria Inez da Silva de Souza. Um sentido para as aparências: cenas e máscaras do/no cotidiano formativo. Educação em Questão. Natal, v. 49, n. 35, p. 180-202, mai/ago, 2014.

PIMENTEL-JÚNIOR, Clívio. A Invenção Cotidiana da Ciência Escolar: sobre rede de saberes e maneiras de instituir práticas pedagógicascurriculares. Teias. Rio de Janeiro, v. 16, n. 42, p. 164-176, jul/set, 2015.

POLANYI, Michael. A lógica da liberdade. Trad. Joubert de Oliveira Brízida. Rio de Janeiro: TopBooks, 2003.

PRETTO, Nelson de Luca. Uma escola sem/com futuro. Campinas: Papirus: 1996.

PRETTO, Nelson de Luca; LIMA JÚNIOR, Arnaud Soares de. Desafios para o currículo a partir das tecnologias contemporâneas In: PRETTO, Nelson de Luca (Org.). Tecnologia e novas educações. Salvador: EDUFBA, 2005.

PRIGOGINE, Ilya. O fim das certezas: tempo, caos e as leis da natureza. São Paulo: UNESP, 1996.

RORTY, Richard. Contingência, ironia e solidariedade. São Paulo: Martins, 2007.

SANTOS, Boaventura de Sousa. A gramática do tempo: para uma nova cultura política. São Paulo: Cortez, 2006.

YOUNG, Michael. Pra quem servem as escolas? Educação Sociedade. Campinas, v. 28, n. 101, p. 1287-1302, set./dez. 2007.

Doutorando Clívio Pimentel Júnior

Universidade Federal da Bahia - Brasil

Programa de Pós-Graduação em Educação

Professor Substituto do Departamento de Educação II

Membro do Grupo de Pesquisa Formação em Exercício de Professores - FEP/FACED/UFBA.

E-mail: clivio.pimentel@gmail.com 


\section{Dr ${ }^{a}$. Maria Inez da Silva de Souza Carvalho} Universidade Federal da Bahia - Brasil

Programa de Pós-Graduação em Educação

Professora Associada do Departamento de Educação II

Líder do Grupo de Pesquisa Formação em Exercício de Professores - FEP/FACED/UFBA

E-mail: misc@ufba.br

Recebido em: 03 de novembro de 2015

Aprovado em: 24 de abril de 2016 